Faculdade

de Ciências Econômicas UFRGS
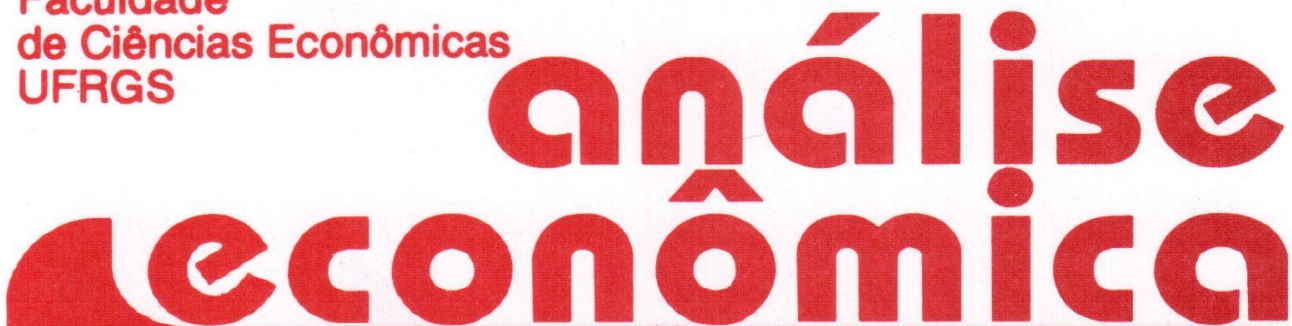

- globalização, Blocos REgIONAIS E O SETOR AGRÍ́COLA NO MERCOSUL Paulo D. Waquil

- globalização: ReALIdAde E UTOPIA

Gentil Corazza

- DO FOREIGN CURRENCY DEPOSITS DID THEY IMPROVE WELFARE?

Carlos A. Janada

- MACROECONOMIC INSTABILITY AND STRATEGIES OF TRANSNATIONAL CORPORATIONS IN BRAZIL

Reinaldo Gonçalves

- INFRASTRUCTURE, PUBLIC CAPITAL AND GROWTH IN THE BRAZILIAN ECONOMY

Stefano Florissi

+ EFEITOS DO PLANO REAL SOBRE O RIO GRANDE DO SUL Marcelo S. Portugal

- REgIONALIZAÇÃo dA MATRIZ dE INSUMO-PRODUTO E O IMPACTO DO AUMENTO DA PRODUÇÃO DE GRÃOS NO RS E NO BRASIL

Nali de Jesus de Souza

- IMPORTACõES DE LEITE E A PECUÁRIÁ LEITEIRA NO BRASIL Silvinha P. Vasconcelos

- ANPEC: CURSO PREPARATÓRIO

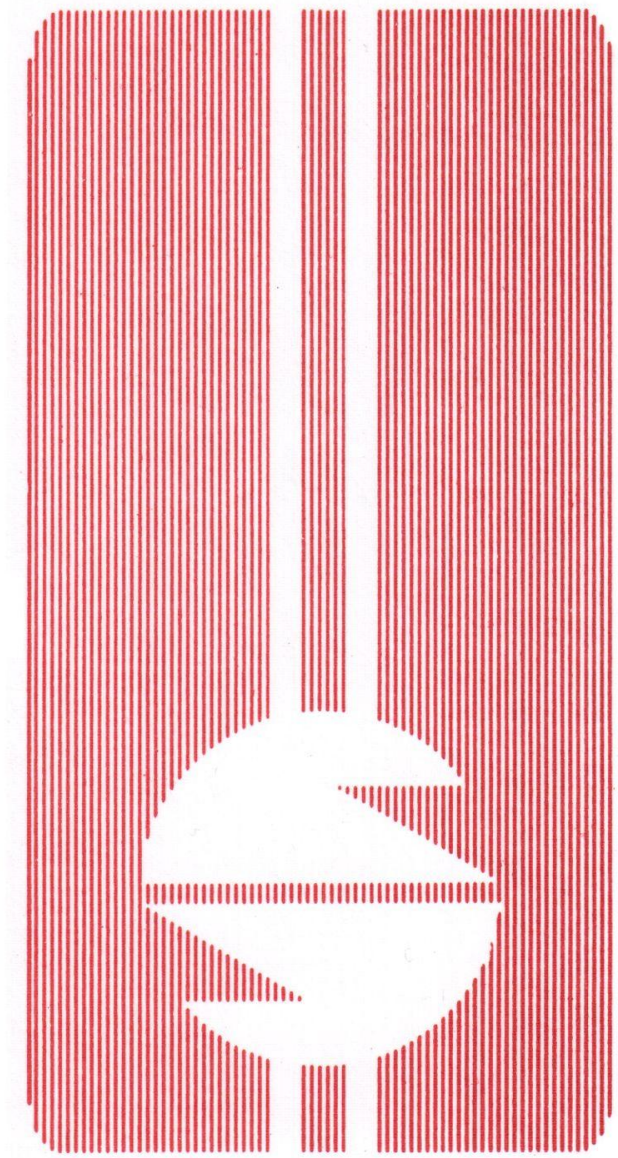


UNIVERSIDADE FEDERAL DO RIO GRANDE DO SUL

Reitor. Prof ${ }^{a}$. Wrana Maria Panizzi

FACULDADE DE CIÊNCIAS ECONÔMICAS

Diretor. Prof'. Otília Beatriz Kroeff Carrion

CENTRO DE ESTUDOS E PEQUISAS ECONÔMICAS

Diretor: Prof. Paulo Alexandre Spohr

DEPARTAMENTO DE CIÊNCIAS ECONÔMICAS

Chefe: Prof. Gentil Corazza

CURSO DE PÓS-GRADUAÇÃO EM ECONOMIA

Coordenador. Prof. Marcelo Savino Portugal

CURSO DE PÓS-GRADUAÇÃO EM ECONOMIA RURAL.

Coordenador. Prof. Carlos Guilherme A. Mielitz Netto

CONSELHO EDITORIAL: Achyles Barcelos da Costa, Aray Miguel Feldens, Carlos Augusto Crusius, Carlos Guilherme A. Mielitz Netto, Eugênio Lagemann, Fernando Ferrari Filho, Gentil Corazza, Marcelo Savino Portugal, Nali de Jesus de Souza, Otília Beatriz K. Carrion, Paulo Alexandre Spohr, Paulo Dabdab Waquil, Pedro Cezar Dutra Fonseca, Roberto Camps Moraes, Valter José Stülp, David Garlow (Wharton Econometrics Forecasts Association, E.U.A.), Edgar Augusto Lanzer (UFSC), Eleutério F. S. Prado (USP), Fernando de Holanda Barbosa (FGV/RJ), Gustavo Franco (PUC/RJ), João Rogério Sanson (UFSC), Joaquim Pinto de Andrade (UnB), Juan H. Moldau (USP), Werner Baer (Univ. de Illinois, E.U.A.).

COMISSÃO EDITORIAL: Fernando Ferrari Filho, Gentil Corazza, Paulo Dabdab Waquil, Marcelo Savino Portugal, Roberto Camps Moraes.

EDITOR: Nali de Jesus de Souza

SECRETARIA: Cláudia Porto Silveira, Jeferson Luis Bittencourt. Revisão de textos: Vanete Ricachescki.

FUNDADOR: Prof. Antônio Carlos Santos Rosa

Os materiais publicados na revista Análise Econômica são da exclusiva responsabilidade dos autores. É permitida a reprodução total ou parcial dos trabalhos, desde que seja citada a fonte. Aceita-se permuta com revistas congêneres. Aceitam-se, também, livros para divulgação, elaboração de resenhas e recensões. Toda correspondência, material para publicação (vide normas na terceira capa), assinaturas e permutas devem ser dirigidos ao seguinte destinatário:

PROF. NALI DE JESUS DE SOUZA

Revista Análise Econômica

Av. João Pessoa, 52

CEP 90040-000 PORTO ALEGRE - RS, BRASIL

Telefones: (051) 316-3348 e 316-3440

Fax: (051) 225-1067 


\section{GLOBALIZAÇÃO: REALIDADE E UTOPIA}

Gentil Corazza*

\section{SINOPSE}

A globalização é tema de muitas controvérsias. Para muitos, ela significa que tudo mudou e é preciso aceitar incondicionalmente a nova realidade. Para outros, trata-se de um mito para justificar politicas indefensáveis. Difícil é entender a natureza e a profundidade das mudanças em meio a muitas continuidades. O objetivo deste artigo é esclarecer os aspectos realmente novos entre as muitas mudanças trazidas pela globalização. Defende-se que o traço novo mais importante da globalização reside na ampliação do poder monetário privado frente ao poder estatal.

\section{INTRODUÇÃO}

A globalização se tornou a palavra da moda e, ao mesmo tempo, um tema muito controverso e polêmico, cuja compreensão tem provocado os mais diversos posicionamentos.

De uḿ lado, a globalização significa que o mundo mudou radicalmente e, por isso, ela não é apenas a palavra da moda, mas também uma palavra de ordem, uma exigência de que todos aceitem incondicionalmente as mudanças e ponham em prática as políticas adequadas a esse mundo liberalizado e sem fronteiras, se quiserem usufruir de suas benesses. Esta é, sem dúvida, uma postura ideológica de quem usa a globalização tanto para eximir-se de explicar a natureza das mudanças como para justificar políticas muitas vezes indefensáveis.

De outro, um esforço para negar a realidade efetiva do fenômeno da globalização, como se nada tivesse mudado no modo de operar do capitalismo internacional. Para estes, a globalização não é um fenômeno novo, mas um processo tão antigo quanto o próprio capitalismo. É apenas uma nova palavra para traduzir a tendência histórica da internacionalização que opera desde os primórdios do capitalismo. Não negam que haja mudanças importantes, mas afirmam que tais mudanças se dão dentro de um quadro de continuidade. Não há nada de essencialmente novo na globalização.

* Doutor em Economia pela UNICAMP e Professor Adjunto do Departamento de Economia da UFRGS.

\begin{tabular}{|c|c|c|c|}
\hline $\begin{array}{c}\text { Cód. AEA } \\
\mathbf{4 1 0}\end{array}$ & $\begin{array}{c}\text { Palavras-chave: } \\
\text { globalização, neoliberalismo, comércio exterior. }\end{array}$ \\
\hline ANÁLISE ECONÔMICA & ANO 15 & Março de 1997 & p. 16-27 \\
\hline
\end{tabular}


Em terceiro lugar, aqueles que, ultrapassando tanto a visão negativa de que nada mudou, como a visão puramente ideológica de que tudo mudou, procuram analisar os novos fenômenos para esclarecer o significado, o alcance e os limites das mudanças provocadas pela globalização. Buscam, também, avaliar os impactos da globalização sobre a vida cotidiana das nações, das empresas e das pessoas.

O objetivo deste artigo é o de analisar o fenômeno da globalização e as controvérsias que o mesmo vem suscitando, procurando salientar os aspectos realmente novos da globalização. Entendemos que as transformações atuais do capitalismo significam mudanças na continuidade, mas também mudanças com descontinuidade. A globalização tem um conteúdo ideológico, mas também um conteúdo real de mudança. A questão fundamental consiste em precisar quais são as peculiaridades históricas dessas mudanças. É o que tentaremos fazer neste trabalho.

\section{IDEOLOGIA E REALIDADE DA GLOBALIZAÇÃO}

A globalização é um fenômeno, cujas aparências, à primeira vista, sugerem que o mundo, criado pelo homem, assumiu as dimensões e as propriedades naturais do globo terrestre. Um mundo globalizado seria um mundo sem fronteiras artificiais, criadas pelo homem, como os Estados nacionais, com suas instituições e suas politicas, e os organismos e regras de convivência internacionais. A globalização significaria a completa integração econômica e a mais ampla liberalização comercial e financeira. Numa palavra, a vigência natural da economia de mercado.

Este é o discurso da globalização, um discurso ideológico, gerador de um consenso global, que pretende anular qualquer possibilidade de dissenso e de crítica, um caminho de mão única, que todos deveriam trilhar, para conseguir os frutos do desenvolvimento econômico e social, e uma verdade única, que todos deveriam conhecer e seguir.

Para a ideologia da globalização, o fim das economias socialistas significou a vitória da economia de mercado, uma nova era de prosperidade, paz e democracia sem precedentes, uma nova idade de ouro do capitalismo mundial, onde os mercados sem fronteiras, dominados por empresas globais, criarão sua própria ordem privada. O sistema econômico e político norte-americano tornou-se modelo para o resto do mundo. O capitalismo parece ter triunfado $e$ parece dominar todo o globo, com promessas de uma vida decente para todos.

É este o conteúdo ideológico e a retórica da globalização. No entanto, será ela pura retórica e ideologia?

Para alguns autores, como Batista Jr (1996), a globalização é pura retórica e ideologia. $\mathrm{Na}$ verdade, afirma ele, "a retórica da globalização virou uma espécie de biombo para políticas econômicas indefensáveis". No seu intuito de 
negar realidade objetiva ao fenômeno da globalização, afirma que: "De um ponto de vista histórico, globalização é uma nova palavra para um processo que remonta à expansão da civilização européia a partir do final do século XV".

No entanto "esta tendência está muito longe de dissolver as fronteiras entre economias nacionais ou ameaçar a sobrevivência do Estado Nacional". Para ele, não há fundamento na "tese de que esteja emergindo um sistema econômico novo, de caráter supranacional", pois o processo atual tem precedentes históricos, é menor do que o propalado e a economia mundial é, hoje, muito menos integrada do que foi no período de 1860 a 1914.

Como prova disso, lembra que a demanda e os mercados internos ainda são preponderantes na economia mundial, sendo responsáveis por $90 \%$ do emprego na maioria dos paises; por sua vez, a poupança interna responde por cerca de $95 \%$ da formação do capital, sendo que sua maior parte fica nos paises de origem; por exemplo, os Estados Unidos têm apenas $6 \%$ de seus ativos fora do país, a Alemanha, $5 \%$ e o Japão, $9 \%$.

Embora reconhecendo "aspectos inéditos no plano tecnológico, em áreas como informática, telecomunicações e finanças", no atual processo de globalização, conclui que: "Em suma, a globalização é um mito que exagera o peso das forças econômicas de âmbito internacional"(Batista Jr, 1996, p. 11).

Diferente é a posição de Coutinho (1996), ao afirmar que a globalização possui um conteúdo ideológico, mas apresenta, também, "um conteúdo objetivo nitido", pois a economia mundial sofreu rápidas e importantes transformações nos anos 80 , que configuram "uma etapa nova e mais avançada de progresso tecnológico e de acumulação financeira de capital", ou seja, "um estágio mais profundo e intenso de internacionalização da vida econômica, social, cultural e política", um novo padrão de organização da produção e da gestão; um aprofundamento da centralização de capital, com poucos atores globais, novos oligopólios mundiais, policentrismo econômico, interpenetração patrimonial, aumento da riqueza mobiliária mundial, ausência de padrão monetário mundial estável, com taxas cambiais flutuantes, ampliação da especulação, desenvolvimento de mecanismos de proteção de risco e potencialização do risco sistêmico. ${ }^{\dagger}$

Da mesma forma, Chesnais (1996, p. 13) não nega a realidade da globalização, embora prefira chamá-la de "mundialização do capital", a qual significa "bem mais do que apenas outra etapa no processo de

\footnotetext{
' Outros autores, como Zini Jr (1996), Gonçalves (1996) e Bauman (1996a) apontam caracteristicas semelhantes.

2 "A expressão 'mundialização do capital' è a que corresponde mais exátamente à substância do termo inglês 'globalização', que traduz a capacidade estratégica de todo grande grupo oligopolista, voltado para a produção manufatureira ou para as principais atividades de serviços de adotar, por conta própria, um enfoque e conduta 'globais'. (Chesnais, 1996, p. 17).
} 
internacionalização, tal qual a conhecemos a partir de 1950". Trata-se de "nova configuração do capitalismo mundial e dos mecanismos que comandam seu desempenho e regulação." Aponta que novos modos de organização da produção, liberalização e desregulamentação, combinadas com as novas tecnologias de comunicação, "decuplicaram a capacidade intrínseca do capital produtivo de se comprometer e descomprometer, de investir e desinvestir; numa palavra, sua propensão à mobilidade." (Chesnais, 1996, p. 28).

Observamos, através dessas colocações, que a globalização é um complexo processo de mudanças estruturais, que envolve múltiplas dimensões.

Primeiro, uma dimensão econômica, micro e macroeconômica, tanto financeira quanto produtiva. Embora os aspectos macroeconômicos da globalização sejam os mais evidentes, ela é impulsionada por fatores de natureza microeconômica, principalmente a velocidade da incorporação das inovações tecnológicas ao processo produtivo, o que exigiria elevado nível de rotatividade de produtos e serviços. ${ }^{3}$

Tornar viável economicamente estas inovações seria o imperativo microeconômico que impulsionaria a dinâmica macroeconômica da globalização, ou seja, a substituição do rigido padrão taylorista-fordista de organização industrial, bem como as instituições do Estado de bem-estar e do Estado desenvolvimentista. Por outro lado, esta exigência de flexibilização seria responsável também pelo maior desenvolvimento das finanças e o domínio da lógica financeira sobre as atividades produtivas. Chesnais

Chesnais (1996, p. 15) destaca que "é na produção que se cria riqueza, ...mas é a esfera financeira que comanda ...". A "financeirização' da riqueza, de que fala Braga (1993), seria uma exigência dessa flexibilização ou dessa capacidade de investir e desinvestir, esta necessidade de descongelar o capital para que possa mover-se livremente num mundo sem fronteiras, o seu espaço mais adequado e natural.

Segundo, uma dimensão política, na medida em que dilui as fronteiras entre paises e afeta a soberania dos Estados nacionais e sua capacidade de fazer política econômica.

Terceiro, uma dimensão social, ao colocar em xeque direitos sociais e conquistas históricas da sociedade organizada.

Finalmente, uma dimensão cultural, na medida em que permite uma maior difusão e integração das culturas e também uma maior dominação das culturas dominantes.

A globalização é, também e principalmente, um fenômeno contraditório, ou seja, não se trata de um movimento linear, guiado por forças inexoráveis, que

${ }^{3}$ Ver Castro (1996), 
vão padronizando e igualando todas as situações econômicas, sociais e institucionais mundo a fora. Parece claro que o mundo se globaliza, mas também é notório que o mundo atual se fragmenta em pedaços, por uma explosão de novos nacionalismos e se fecha em blocos regionais; a crescente liberalização é acompanhada por novos protecionismos de toda ordem; ${ }^{4} 0$ crescimento sem precedentes da riqueza é acompanhado de uma também crescente desigualdade de sua distribuição entre ricos e pobres; o desenvolvimento da tecnologia e da produtividade é seguido de enorme desemprego estrutural; a contradição entre os sempre maiores ganhos financeiros e a produção real, entre os mecanismos de proteção contra os riscos e a globalização do risco financeiro.

Entre os aspectos contraditórios da globalização, deve-se destacar o seu confronto com o movimento de regionalização. Como entender a coexistência desses dois processos, o de globalização e 0 de regionalização, aparentemente contraditórios? Em que medida são eles convergentes ou contraditórios?

As opiniões são diversas. Há os que acentuam as contradições entre os dois processos, pois vêem a formação de blocos regionais como uma ação defensiva e protetora dos valores regionais contra a globalização. O processo de integração regional seria uma resposta ao desafio da globalização.

Esses dois processos teriam também motivações diferentes: enquanto a globalização se apoiaria mais em fundamentos econômicos, como reflexo das estratégias empresariais, a integração regional obedeceria antes de tudo a decisões politicas. Nessa ótica, embora possa haver convergência no curto prazo, no longo prazo acabaria se impondo a lógica da globalização sobre os processos de integração regional.

Para outros autores, porém, existiria convergência e complementaridade dos dois processos. Tavares (1993) a eles se refere como a "globalização regionalizada". Na mesma perspectiva, Coutinho (1996) afirma que as empresas transacionais tornaram-se "agentes ativos dos processos regionais de integração comercial", pois "suas estratégias de produção e mercados são primordialmente regionais" e "suas estratégias tecnológicas e financeiras permanecem sendo eminentemente globais".

As grandes empresas são, ao mesmo tempo, agentes do processo de globalização e líderes do processo de formação de blocos regionais. "Neste sentido, não existe contradição e sim complementaridade entre os movimentos de globalização e de regionalização da economia mundial" (Coutinho, 1996, p.

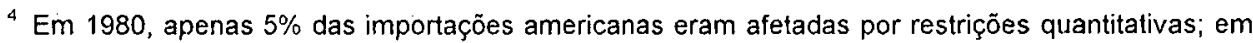
1986, esse percentual já se elevava para 18\%. A Europa e muitos outros paises também intensificaram 0 uso de restrições não tarifárias, de tal forma que, segundo estimativas, $40 \%$ do comércio mundial poderia ser apelidado de "comércio gerenciado"
} 
Gilpin (1994) também vê o processo de globalização e de regionalização como um único processo dialético, que compreende tanto os aspectos convergentes como os divergentes. Acentua também as diferenças entre os processos de integração regional na Europa, na América do Norte e no Leste Asiático. Entende que na Europa a integração econômica é mais profunda e constitui um projeto politico, com o objetivo de fortalecer suas economias e empresas para a competição global.

Já no caso do Nafta, a procura de acordos bilaterais por parte dos Estados Unidos estaria associada ao aparente fracasso da Rodada Uruguaia do Gatt e refletiria também o declínio econômico do pais e as dificuldades enfrentadas com seus parceiros comerciais europeus e japoneses. Ou seja, o regionalismo do Nafta assume mais um caráter defensivo.

No Leste Asiático, porém, as economias dependem muito mais dos mercados globais do que dos mercados regionais e as diferenças econômicas, políticas e culturais são muito maiores do que nos demais casos. Aqui, o regionalismo converge mais com a globalização, pois um fechamento regional seria prejudicial a essas economias.

Entende, também, Gilpin que o regionalismo atual, diferentemente do de outras épocas, que se inclinou mais para o fechamento e o conflito comercial entre blocos, se caracteriza pela abertura e integração, pois entende-se que a criação de um ambiente competitivo interno a um bloco regional fortalece as empresas para competir no mercado global, permitindo que alcancem economias de escala e competitividade globais. Neste sentido, a integração regional deve ser vista como um reforço à capacidade competitiva global. Os blocos regionais procuram ampliar os acordos comerciais entre si e as empresas transacionais, em sua estratégia global, reforçam seus investimentos nos blocos regionais, de modo a forçar as convergências entre os dois processos. Dessa forma, a globalização e o regionalismo se realizam ao mesmo tempo e se reforçam mutuamente. No entanto, alerta Gilpin, não se pode afastar a perspectiva de fechamento e conflito regional. Seu desfecho final seria, ainda, incerto.

Em conclusão, além de sua dimensão ideológica, a globalização.aponta para uma realidade em processo de grandes transformações. Embora não se conheça a exata natureza dessas transformações, não se pode discordar de que "alguma coisa significativa se alterou no modo como o capitalismo tem funcionado a partir de, aproximadamente, 1970" (Harvey, 1989, p. 163). A pergunta que fazemos é se essas mudanças traduzem apenas tendências históricas, ou se contêm alguma novidade peculiar aos novos tempos? Esta é a questão da próxima seção. 


\section{NOVIDADE E UTOPIA DA GLOBALIZAÇÃO}

Arrighi (1996, p. XII) adverte que, se quisermos entender nosso sistema econômico, precisamos aprofundar o "entendimento da relação entre o dinheiro e o poder na formação de nossa época". Considerando que esta relação, entre Estado e dinheiro, é uma das características essenciais de nosso sistema econômico, é sobre possiveis mudanças nessa relação que devemos procurar o que existe de realmente novo nas transformações trazidas pela globalização, como sugere Harvey (1994, p. 184): “... se quisermos procurar alguma coisa verdadeiramente peculiar (em oposição ao 'capitalismo de sempre') na atual situação, devemos concentrar o nosso olhar nos aspectos financeiros da organização capitalista e no papel do crédito". O mesmo autor completa sua afirmação, dizendo que:

É verdade que o equilibrio entre o poder financeiro e o poder do Estado no capitalismo sempre fora delicado, mas o colapso do fordismo-keynesianismo significou fazer o prato da balança pender para o poder do capital financeiro (Harvey, 1994, p. 156).

A partir dessas colocações de Arrighi e de Harvey, queremos sugerir que o descolamento progressivo entre o poder monetário e o poder estatal, cuja unidade, tensa e conflitiva, marcou o capitalismo, desde seus primórdios, parece ser o traço novo dessa transição histórica. A formação de um espaço monetário e financeiro de decisão privada, fora do alcance do poder estatal, se afigura como algo, se não totalmente inédito na história do capitalismo, pelo menos inteiramente novo em sua história recente.

Embora o poder monetário privado dos bancos e empresas sempre tenha existido, desde o início do capitalismo, quando o monopólio estatal do dinheiro se tornou um dos pilares da formação do Estado nacional, esse poder monetário privado nunca havia se mostrado tão forte e independente como na atualidade. A formação e o desenvolvimento desse espaço quase soberano de atuação do dinheiro privado se deu no bojo da crise de hegemonia do dólar e das instituições internacionais de Bretton-Woods, que regeram o desenvolvimento da economia mundial nos anos 50 e 60 .

$\mathrm{Na}$ verdade foi o fim da conversibilidade dólar-ouro, decidido por Nixon em 1971, e a adoção de taxas flexíveis de câmbio, em 1973, que representaram o colapso daquele sistema. Com o câmbio flutuante, a liquidez das reservas plurimonetárias no âmbito do euromercado, a liberalização e o surto de inovações financeiras, os governos e os Bancos Centrais perderam significativa parcela de seu poder de controle sobre a moeda, o crédito e as finanças privadas. Como afirma Braga:

Há uma perda do monopólio do crédito e do sistema de pagamentos pelo sistema bancário: autoridades monetárias e bancos centrais $A$ oferta de crédito e o sistema de pagamentos não 
estão mais controlados pelos bancos centrais e comerciais nacionais, e há uma forte tendência à financeirização com moedas privadas (Braga: 1993, p. 36-37).

Esta transição histórica da rigidez do fordismo-keynesianismo para um período de "acumulação flexivel", se caracterizou pela crise da rigidez dos investimentos de longo prazo, a larga escala da produção em massa, a rigidez dos mercados e dos contratos de trabalho, a rigidez dos compromissos estatais e a rigidez das taxas fixas de câmbio. "Descle então, todas as nações têm estado à mercê da disciplina financeira, seja por efeitos da fuga de capitais, seja por pressões institucionais diretas" (Arrighi, 1996, p 3).

É esse extraordinário desabrochar e transformação dos mercados financeiros que Harvey aponta como a verdadeira novidade do capitalismo nas décadas de 1970 e 1980 . Acumulação flexivel significa a "financeirização" ou um verdadeiro "descongelamento" do capital, acompanhado da recriação da produção artesanal e dos ensaios de coordenação via mercado. Tudo isto são tentativas de solução financeira de uma crise que afetou profundamente o capitalismo a partir dos anos 70 .

Nessa mesma perspectiva, Vacca (1996, p. 74) afirma também que a globalização financeira inaugurou "um capitulo novo - talvez decisivo - da crise da soberania econômica: a ruptura da ligação entre a produção (e a circulação) da riqueza e o território, e portanto a crise da soberania fiscal do Estado". Ele aponta três fatores dessa crise: primeiro, a criação de um "mercado financeiro internacional que foge ao controle dos Estados"; segundo, o comando das atividades industriais pelas atividades financeiras; terceiro, o progressivo domínio do comércio internacional pelo comércio intracorporações. Resumo disso tudo seria a crise do bloco Estado - nação - mercado, ou melhor, a ruptura da cadeia política entre Estado, riqueza e território.

As colocações anteriores sobre as rupturas entre Estado e dinheiro, entre riqueza e território nacional, sinalizam para aquilo que denominamos de utopia da globalização. A globalização se contrapõe à ordem institucional, na medida em que pretende erigir-se como ordem privada, construida unicamente sobre as leis de mercado, independentemente de acordos, regras ou instituições internacionais. Isso significaria o completo dominio da economia sobre a política, onde não se necessitaria mais do Estado, nem de suas instituições, nem de suas politicas, pois valeriam unicamente as regras da competitividade e da eficiência estritamente econômicas balizadas por padrões globais.

$\mathrm{Na}$ história do capitalismo tivemos duas ordens internacionais. A primeira, de caráter mais convencional, foi a chamada ordem britânica, calcada no regime do padrão ouro, na supremacia industrial e na orquestração das finanças internacionais pelo Banco da Inglaterra. A segunda, de caráter mais formal, a ordem de Bretton-Woods, nasceu de um acordo internacional, liderado pelos Estados Unidos e sancionado pela supremacia do dólar como 
moeda mundial.

O processo de globalização, principalmente na sua dimensão financeira, pode ser visto tanto como causa, quanto como conseqüência da crise da ordem internacional de Bretton-Woots. Em que medida a economia e as finanças internacionais poderão sobreviver sem uma ordem institucional, ou sem algum tipo de poder mundial, mesmo que constituido pelo poder político das grandes potências, só a história futura do capitalismo poderá responder.

No entanto, os exemplos da história passada e recente indicam claramente tratar-se de uma verdadeira utopia pensar que as forças da globalização possam organizar e reger sua própria ordem privada, com base apenas nas regras do mercado. Basta lembrar as crises bancárias dos anos 70 e 80 e, mais recentemente, a crise mexicana de 1994, para ver que, sem a intervenção dos Bancos Centrais, seria inevitável uma crise generalizada de conseqüências imprevisiveis.

Numa era de globalização, caberia perguntar quem são os verdadeiros atores globais? As grandes empresas transnacionais (ETNs) ou os Estados nacionais? Grande parte da literatura não hesita em afirmar que são as primeiras. Não resta dúvida de que a iniciativa dạs ações e a dinâmica da globalização pertencem cada vez mais às ETNs.

A concorrência globalizada forçou o processo de concentração econômica e de liberalização comercial e financeira a tal ponto que a balança do poder internacional pende cada vez mais para o lado do capital privado. Se, por um lado, isto é verdade, por outro, também é verdade que as ETNs não abdicam de suas bases e passaportes nacionais, nem dispensam ajuda de seus governos de origem. Além disso, os acordos e tratados internacionais sobre comércio pertencem ainda à esfera exclusiva dos governos.

Por essas razões, parece falsa a idéia de que seria possível ou desejável prescindir do Estado e das instituições, quer em nivel das sociedades nacionais, que nas relações internacionais, pois "...foi o Estado nacional, bem delimitado, que proporcionou ao capitalismo sua oportunidade de desenvolvimento ... (Weber, apud Arrighi, 1996, p. 12). Neste sentido lembra ainda Arrighi (1996, p. 11), que, historicamente, "o capitalismo só triunfa quando se identifica com o Estado, quando é o Estado".

Estaria agora o capitalismo globalizado em condições de prescindir do Estado nacional e de suas instituições internacionais?

\section{CONCLUSÃO}

As economias nacionais nunca foram autarquias, embora tenham sempre 
lutado por uma maior autonomia em relação às restrições externas. De uma forma ou de outra, em maior ou em maior grau, sempre estiveram articuladas ao desenvolvimento e às restrições da economia internacional. Seu grau de liberdade variou de acordo com a forma de sua articulação externa e com o dinamismo de suas atividades internas.

De um modo geral, pode-se afirmar que, paradoxalmente, esse raio de manobra foi maior quando a economia internacional esteve submetida a algum tipo de ordem internacional. Foi assim, durante o periodo da ordem britânica, em que vigoraram as regras do padrão ouro, e durante a ordem americana, em que foram respeitadas as regras e acordos de Bretton-Woods.

No período entre-guerras, a desordem internacional, na realidade, impôs muito mais restrições ao desenvolvimento das economias nacionais do que as rígidas regras do padrão ouro e o domínio do império britânico. Da mesma forma, os acordos de Bretton-Woods e a dominação americana permitiram um elevado grau de liberdade e oportunidades de crescimento para as economias nacionais.

Paradoxalmente, a partir dos anos 70 , com a crise da hegemonia americana e o fim do sistema financeiro de Bretton-Woods, as taxas flexiveis de câmbio e a crescente liberalização do comércio e das finanças internacionais, em vez de aumentarem os graus de liberdade para as políticas econômicas nacionais, significaram, na verdade, uma restrição ainda maior. $O$ processo de globalização financeira coloca em xeque qualquer pretensão de autonomia para essas políticas.

A produção material de bens e serviços das economias nacionais está cada vez mais submetida à lógica financeira e à lógica da globalização. Se quisermos entender como funcionam as economias nacionais integradas ao capitalismo globalizado, precisamos entender a lógica da globalização financeira, que subordina cada vez mais as economias, as políticas e as sociedades nacionais.

Como lembra lanni (1995, p. 189), a globalização coloca um novo desafio epistemológico para a ciência econômica que entendia a economia internacional como apêndice das economias nacionais. Agora é o funcionamento destas últimas que deve ser entendido a partir da lógica global. Nessa economia globalizada e submetida à sua lógica financeira, a forma de integração das economias nacionais pode ditar os rumos de seu desenvolvimento.

Ao longo de sua história, o Brasil passou por distintos padrões de inserção internacional e, em todas elas, sempre soube aproveitar as oportunidades que as restrições externas lhe permitiam. Sem falar na fase primário-exportadora, é principalmente a partir de 1930, com o processo de substituição de importações, que a economia brasileira soube contornar as restrições externas 
e fazer delas um estímulo para sua industrialização e desenvolvimento.

Mais recentemente, registramos momentos críticos em que a economia brasileira sofreu mais reveses do que obteve sucessos: o choque do petróleo nos anos 70, a crise da dívida externa nos anos 80 e agora, nos anos 90 , os movimentos especulativos dos capitais financeiros internacionais. Todos esses fatos têm se constituído em fatores desestabilizadores externos, que o Brasil não tem sabido enfrentar, o que demonstra a fragilidade externa crescente pela qual passa nosso país.

Coutinho (1996) assinalou com propriedade os pontos frágeis da economia brasileira para enfrentar os desafios colocados pela globalização: primeiro, a estratégia de estabilização via valorização cambial significa um enfraquecimento da capacidade competitiva comercial do país; segundo, apesar do grande avanço da reestruturação industrial e dos ganhos de produtividade, o reduzido porte de nossos grupos industriais representa outro ponto de fragilidade face aos competidores globais; por último, a inexistência de um sistema de crédito de longo prazo (além do sistema público do BNDES) dificulta os grandes investimentos produtivos e o processo de centralização de capital.

Face a essas fragilidades da economia brasileira e ao processo de globalização, qual a postura do Governo brasileiro? Abertura da economia, ancoragem no dólar, estabilização a qualquer custo. Mais que isso: resignação face aos imperativos da globalização, como se pode deduzir do discurso do Presidente Fernando Henrique Cardoso na Índia (1996). Resignar-se face à globalização significa confiar que as forças de mercado criarão a ordem e o desenvolvimento. Proceder dessa forma significa submeter-se à dimensão ideológica e utópica da globalização, correndo os riscos a ela associados, sem garantia de poder usufruir das oportunidades e benefícios que a sua dimensão real poderia oferecer.

\section{BIBLIOGRAFIA}

AMORIN, Celso. Os frágeis pilares da nova ordem. In; BAUMANN (1996).

ARRIGHI, Giovanni. O longo século XX. São Paulo. Unesp, 1996.

BATISTA JR, Paulo N. A cortina de fumaça da "globalização". Jornal do Economista, n. 92,

Suplemento Especial, Corecon-SP, Setembro, 1996.

Entreguismo e "globalização". Folha de São Paulo, 29.08, 1996a

BAUMANN, Renato (org.) O Brasil e a economia global. São Paulo: Campus, 1996.

Uma visão econômica da globalização, 1996a. In. BAUMANN (1996).

BRAGA, José Carlos. A financeirização da riqueza. Economia e Sociedade, Campinas: Unicamp, Instituto de Economia, n. 2, 1993.

CARDOSO, F Henrique. Discurso sobre a globalização feito na Índia (Publicado sob o título: "FHC discute as consequências da globalização"). Gazeta Mercantil, 28 jan 1996.

CHESNAIS, François A mundialização do capital São Paulo. Xamã, 1996.

COUTINHO, Luciano. A fragilidade do Brasil em face da globalização, 1996. In: BAUMANN (1996).

O capital internacional e a presença brasileira na globalização. Jornal do Economista $n$. 
92, Suplemento Especial, Corecon-SP, Setembro, 1996a.

CASTRO, Antônio Barros de (1996). Fundamentos microeconômicos da globalização. Folha de São Paulo, 22 dez.1996.

DUPAS, Gilberto Globalização: as oportunidades e os riscos. São Paulo, Gazeta Mercantil 9 e 10 dez. 1995

GILPIN, Robert. A nova ordem politica e econômica mundial. In: VELLOSO e MARTINS (1994)

HARVEY, David. Condição Pós-Moderna. São Paulo: Loyola, 1994

IANNI, Octávio Teorias da Globalização. São Paulo: Civilização Brasileira, 1995.

TAVARES, Maria da Conceição. Tendências de globalização, crise do Estado nacional e seus impactos sobre o Brasil. Rio de Janeiro: Cadernos da ANGE, Textos Didáticos n. 6, 1993.

VACCA, Giuseppe. Pensar o mundo novo. São Paulo: Ática, 1996.

VELLOSO, João Paulo dos Reis e MARTINS, L. (orgs.). A nova ordem mundial em questão. Rio de Janeiro: José Olympio, 1994

\section{ABSTRACT}

\section{GLOBALIZATION: REALITY AND UTOPIA}

Globalization is a subject of several disputes. For many people, it means that everything changed and it is necessary to accept the new situation. For others, it is a mith to justify indefensible policies. It is hard to understand the nature and depth of the changes in the middle of many continuities. The objective of this paper is to clarify the actually new aspects among the several changes brought about by globalization. It is indicated that the most important new aspect is the amplification of the private monetary power in opposition to the state power. 